\title{
journal of controlled

\section{Comparative study of GDNF delivery systems for the CNS: polymer rods, encapsulated cells, and lentiviral vectors}

\author{
Jean-Charles Bensadoun $^{\mathrm{a}, \mathrm{b}, 1}$, Luis Pereira de Almeida ${ }^{\mathrm{b}, \mathrm{c}, 1}$, Eric G. Fine ${ }^{\mathrm{b}}$, \\ Jack L. Tseng ${ }^{\mathrm{b}}$, Nicole Déglon ${ }^{\mathrm{a}, \mathrm{b}}$, Patrick Aebischer ${ }^{\mathrm{a}, \mathrm{b}, *}$ \\ ${ }^{a}$ Institute of Neurosciences, Swiss Federal Institute of Technology Lausanne EPFL, CH-1015 Lausanne, Switzerland \\ ${ }^{\mathrm{b}}$ Division of Surgical Research and Gene Therapy Center, Lausanne University Medical School, Lausanne, Switzerland \\ ${ }^{\mathrm{c}}$ Laboratory of Pharmaceutical Technology, Faculty of Pharmacy and Center for Neuroscience, University of Coimbra, Coimbra, \\ Portugal
}

\begin{abstract}
Glial cell line-derived neurotrophic factor (GDNF) holds great promise for the treatment of Parkinson's disease. In humans, its intracerebroventricular administration leads to limiting side effects. Direct parenchymal delivery using mechanical means, or cell and gene therapy represent potential alternatives. In the present study, a representative of each of these three approaches, i.e. polymer rods, genetically modified encapsulated cells and lentiviral vectors was analyzed for its ability to release GDNF in the striatum of rats. One week post-surgery, GDNF was detected over a distance of $4 \mathrm{~mm}$ with all three methods. At 4 weeks GDNF staining diminished with rods and to a lesser extent with encapsulated cells, whereas it increased with lentiviral vectors. Nanogram range of GDNF was measured with all methods at 1 week. At 4 weeks, GDNF levels decreased significantly with rods, whereas they remained stable with encapsulated cells and lentiviral vectors. We conclude that all three methods investigated allow striatal delivery of GDNF, but the time during which it needs to be released will determine the approach chosen for clinical application.
\end{abstract}

(c) 2002 Elsevier Science B.V. All rights reserved.

Keywords: CNS delivery; Neurotrophic factors; Polymer rods; Cell encapsulation; Lentiviral vectors

\section{Introduction}

Neurodegenerative disorders of the central nervous system (CNS) are characterized by a selective and progressive degeneration of neuronal subpopulations leading to severe debilitating clinical symptoms. Current treatments consist mainly in symptomatic

\footnotetext{
*Corresponding author. Tel.: +41-21-693-9521; fax: +41-21693-9520.

E-mail address: patrick.aebischer@epfl.ch (P. Aebischer).

${ }^{1}$ These authors contributed equally to this work.
}

therapies with no effect on the onset or disease progression. Efforts are thus being made to develop neuroprotection or even neuroregenerative strategies. Neurotrophic factors hold the greatest promise to achieve this goal.

Neurotrophic factors (NTFs) are polypeptides known to promote growth, survival and differentiation of neurons during development, as well as plasticity and structural integrity of the adult nervous system. These proteins have demonstrated potent neuroprotective effects on various neuronal populations in experimental models of neurodegenerative 
diseases, such as nerve growth factor (NGF) for Alzheimer's disease (AD), glial cell line-derived neurotrophic factor (GDNF) for Parkinson's disease (PD), or ciliary neurotrophic factor (CNTF) for Huntington's disease (HD) [1,2]. Several clinical trials have been conducted with each of these factors, so far, however, without success. Part of the problems may be related to inefficient delivery technique.

The CNS delivery of NTFs is limited by factors such as (i) their inability to cross the blood-brainbarrier, (ii) their poor stability in a fluid environment, (iii) their limited diffusion through brain parenchyma, and (iv) the side-effects associated with binding to extra-target receptors $[3,4]$. Intracerebroventricular (ICV) administration eliminates the need to bypass the blood-brain-barrier. Poor diffusion within the brain parenchyma $[5,6]$ and occurrence of severe side-effects limit, however, its applicability. Excruciating pain was indeed described with the ICV administration of NGF in AD patients [7,8]; weight loss, nausea and abnormal sexual behavior was reported with the ICV administration of GDNF in PD patients [9]. In contrast, animal experiments have shown that direct parenchymal administration dramatically reduces the occurrence of sideeffects reported with ICV application [5,10]. These observations emphasize the need for localized, sustained delivery of these molecules in specific nuclei of the CNS.

Direct localized CNS delivery is achievable either by mechanical means, or by cell or gene therapy. In the context of this work, we have chosen to compare a representative of each of the three approaches for the intrastriatal delivery of GDNF, a promising trophic factor for the treatment of PD, and deduct the relative advantages/disadvantages of the three delivery techniques.

\section{Materials and methods}

\subsection{GDNF-releasing polymer rods}

Ethylene-vinyl acetate copolymer (EVA; Elvax, Dupont, Wilmington, USA) was cleaned by 20 washes in absolute ethanol followed by 20 washes in sterile distilled water, and finally dried under a mild vacuum. Bovine serum albumin (BSA; Sigma,
Buchs, Switzerland) was sieved to a size $<37 \mu \mathrm{m}$ using scrynel PET33HC meshes (PolyLabo). A 10\% $(\mathrm{w} / \mathrm{v})$ solution of purified EVA in methylene chloride solvent was prepared with $23 \%$ BSA (w/w total) and $1 \%$ recombinant human GDNF (Amgen) (w/w total), vortexed and sonicated until reaching a homogenous solution. The solution was then quickly frozen and placed into a lyophilizer for $48-72 \mathrm{~h}$ until the solvent was completely evaporated. The mixture was pressure extruded at $55^{\circ} \mathrm{C}$ through a cylindrical diameter die, and 10-cm-long rods were kept at $4{ }^{\circ} \mathrm{C}$ in a dessicator until use. Before implantation, $5-\mathrm{mm}$ rods were cut and sterilized by immersion in $0.1 \mathrm{~N}$ hydrochloric acid for $1 \mathrm{~min}, 70 \%$ ethanol for $1 \mathrm{~min}$, and sterile PBS for $2 \mathrm{~min}$.

\subsection{Characterization of the $C_{2} C_{12}-G D N F$ cell line}

The pCI-neo expression vector (Promega, Madison, WI, USA) was modified as previously described [11]. The fragment containing the mutated dihydrofolate reductase gene (DHFR) under the control of the SV40 promoter and the hepatitis virus B $3^{\prime}$ untranslated region (HBV-3' UTR) was obtained from the RP3224D plasmid [12] digested with $P v u I I$. The isolated fragment was subcloned into the pCI-Neo vector digested with BamHI and blunted, using the $\mathrm{T} 4$ polymerase to fill in the protruding ends. The resulting vector pCI-ND was digested with $B g l \mathrm{II}$ and EcoRI to remove the cytomegalovirus (CMV) promoter. The murine phosphoglycerate kinase 1 promoter and a chimeric intron excised from the pCI-PGK-GIP-R/IRES/GLP-1 vector [13] via $B g l \mathrm{II} / E c o$ RI digestion, was subcloned into the $B g l \mathrm{II} / E c o$ RI site of the pCI-ND plasmid, forming the pPI-DN vector. The plasmid pcDNA3 containing the cDNA coding for the human GDNF with a consensus Kozak sequence (a 636 bp fragment: position 1-151 and 1-485 Genbank accession numbers L19062 and L19063) was digested with BamHI/HindIII and blunted. The GDNF fragment was subcloned into the pPI-DN vector digested EcoRI and blunted to create the pPI-DN-KZ-GDNF. Finally the Herpes Simplex Virus thymidine kinase (HSV-tk) gene obtained from the plasmid RP3224D digested with $N o t \mathrm{I}$ was cloned into the $B g l \mathrm{II}$ site of the pPI-DN-GDNF. The final plasmid named pPIDNT-KZ-GDNF was amplified in a standard E. coli 
strain (DH10B) and purified by a cesium chloride gradient. The integrity of the vector was verified by restriction analysis and sequencing.

$\mathrm{C}_{2} \mathrm{C}_{12}$ mouse myoblasts (ATCC; CRL 1772, Rockville, MD, USA), transfected by calcium phosphate precipitation (Mammalian transfection kit, Stratagene, La Jolla, CA, USA) with the pPI-DNThGDNF plasmid, were selected with $0.8 \mathrm{mg} / \mathrm{ml}$ G418 for 2 weeks, and the integrated plasmid was then amplified with increasing concentrations of methotrexate (1 to $200 \mu \mathrm{M}$ ) over 4 weeks. Stability of transgene expression was achieved by alternating cell incubation weekly in media containing either 0.8 $\mathrm{mg} / \mathrm{ml} \mathrm{G} 418$ or $200 \mu \mathrm{M}$ methotrexate for an additional 6 weeks. The $\mathrm{C}_{2} \mathrm{C}_{12}$ engineered cells were then maintained in culture media supplemented with $0.8 \mathrm{mg} / \mathrm{ml} \mathrm{G} 418$. Twenty-five clones isolated by limiting dilution were tested for GDNF secretion by ELISA assay (R\&D Systems, Abingdon, UK) as well as for their differentiation and survival properties in hollow fibers. The clone \#19 producing $\sim 0.26 \mu \mathrm{g} \mathrm{hGDNF} / 10^{6}$ cells/day was selected for further studies.

\subsection{Cell encapsulation}

$\mathrm{C}_{2} \mathrm{C}_{12}$ cells were cultured in DMEM containing $10 \%$ fetal calf serum, $1 \%$ penicillin/streptomycin, and $2 \mathrm{mM}$ L-glutamine (Life Technologies, Paisley, Scotland, UK). After dissociation, cells were suspended at a density of 25,000 cells $/ \mu$ l culture medium. Six microliters $(150,000$ cells $)$ of the cell solution were injected into $500-\mu \mathrm{m}$ inner diameter poly(ether-sulfone) (PES) fibers (5 mm long; AKZOFiber Nobel, Wupperthal, Germany) previously filled with a poly(vinyl) alcohol (PVA) cylindrical matrix (Rippey Corporation, CA, USA). The ends of the fibers were sealed with a polymerized acrylic-based glue (Ablestic Laboratories, NJ, USA) and kept in culture medium at $37^{\circ} \mathrm{C}$ and $5 \%$ carbon dioxide before transplantation.

\subsection{GDNF-expressing lentiviral vectors}

The generation of viral particles was performed with a four-plasmid system as previously described [14]. Briefly, the cDNAs encoding the human GDNF containing a Kozak consensus sequence were cloned in the SIN-W-PGK transfer vectors. The viral particles were pseudotyped with the vesicular stomatitis virus $\mathrm{G}$ protein, and produced by transient transfection of 293T cells. High-titer stocks were obtained by ultracentrifugation, and tested for the absence of replication-competent viral vectors. The GDNF-expressing viral stocks were matched for viral particle content $(\sim 110,000 \mathrm{ng}$ p24 antigen $/ \mathrm{ml}$ as measured by ELISA assay) corresponding to $\sim 3-7 \times 10^{8} \mathrm{TU} /$ $\mathrm{ml}$.

\subsection{Animals}

Adult female Wistar rats (Iffa-Credo, France), weighing 180-200 $\mathrm{g}$ were used in these studies. They were housed in a controlled temperature room that was maintained in a $12 \mathrm{~h} \mathrm{light/dark} \mathrm{cycle.} \mathrm{Food}$ and water were available ad libitum. The experiments were carried out in accordance with the European Community Council directive (86/609/ EEC) for care and use of laboratory animals.

\subsection{Surgical procedure}

Animals were anesthetized with an intraperitoneal injection of sodium pentobarbital $(50 \mathrm{mg} / \mathrm{kg})$ and placed in a stereotaxic frame. Eighteen animals per group were then unilaterally implanted into the striatum with 5-mm-long GDNF-releasing polymer rods $(0.5 \mathrm{~mm}$ anterior to bregma, $3 \mathrm{~mm}$ lateral to the midline, and $7 \mathrm{~mm}$ ventral from the dura), or with 5-mm-long $\mathrm{C}_{2} \mathrm{C}_{12}$-GDNF capsules $(0.5 \mathrm{~mm}$ anterior, $3 \mathrm{~mm}$ lateral, $7.5 \mathrm{~mm}$ ventral), or were injected with $2 \mu \mathrm{l}$ of concentrated lenti-GDNF $(0.5 \mathrm{~mm}$ anterior, 3 $\mathrm{mm}$ lateral, $5 \mathrm{~mm}$ ventral) at the speed of $\sim 0.2$ $\mu \mathrm{l} / \mathrm{min}$.

One week and 4 weeks post surgery, nine animals were sacrificed with an overdose of pentobarbital. Three were perfused transcardially with ice-cold phosphate buffer saline (PBS) containing $0.02 \%$ ascorbic acid, their brains were removed and fresh tissue punches $(2.8 \times 2 \mathrm{~mm})$ in the striatum including the injection site were rapidly collected and kept at $-80{ }^{\circ} \mathrm{C}$ before processing for hGDNF ELISA assay. The remaining six animals were perfused with PBS/ ascorbic acid and with $4 \%$ paraformaldehyde. The brains were post-fixed in a solution of $4 \%$ paraformaldehyde for $24 \mathrm{~h}$ and then placed in $25 \%$ sucrose 
for an additional $24 \mathrm{~h}$. They were then frozen on dry ice and $25 \mu \mathrm{m}$ coronal sections were cryocut throughout the entire striatum and stored at $4{ }^{\circ} \mathrm{C}$ in PBS containing $0.12 \mu \mathrm{M}$ sodium azide.

\section{7. hGDNF ELISA assay}

Brain punches on the ipsi- and contralateral side ( $n=3$ per condition) were collected and processed to measure the amount of hGDNF using an ELISA assay (Promega) as previously described [15].

\subsection{Immunohistochemical detection of $h G D N F$}

In order to evaluate the diffusion of GDNF in the striatum, immunohistochemistry using biotinylated goat anti-human GDNF antibodies (R\&D Systems, Abingdon, UK; 1:250) was performed on $25-\mu \mathrm{m}-$ thick cryosections as previously described [14].

\subsection{Image analysis}

Diffusion of hGDNF was determined by digitizing $18 \mathrm{hGDNF}$-stained sections per animal $(250 \mu \mathrm{m}$ between each section) throughout the entire striatum with a slide scanner and quantifying the optical density with an image analysis public domain program (NIH-Image, Version 1.6.1, National Institutes of Health, USA). Data are expressed as optical density, corresponding to the sum of gray values of all the pixels in the selection. The contralateral side was used to determine the background density. The corpus callosum and the anterior commissure were used as hallmarks to delimit the striatal area.

\subsection{Statistical analysis}

Data were analyzed for significance (set at $P<$ 0.05 ) using analysis of variance (ANOVA) followed by a Scheffe's PLSD post-hoc test (JMP 3.0, SAS Institute, USA).

\section{Results}

\subsection{Diffusion pattern of GDNF in the striatum}

One and 4 weeks following the implantation of polymer rods or hollow fibers, and the injection of lentiviral vectors into the rat striatum, immunohistochemical detection of hGDNF was performed to characterize the diffusion of the NTF throughout this structure (Fig. 1). One week post-surgery, GDNF staining was present over a maximal distance of 4 $\mathrm{mm}$ in the three groups, which almost corresponds to the entire striatum volume according to the rat brain atlas of Paxinos and Watson [16] (Fig. 1A-C). Line source (polymer rods and encapsulated cells), as well as multiple point source (lentiviral vectors) delivery techniques, show a similar pattern of GDNF staining. GDNF detection was restricted to the striatum as delineated by the corpus callosum.

Four weeks post-surgery, GDNF staining was detected over $\sim 2 \mathrm{~mm}$ throughout the striatum in the case of polymer rods (Fig. 1D), $3 \mathrm{~mm}$ with the

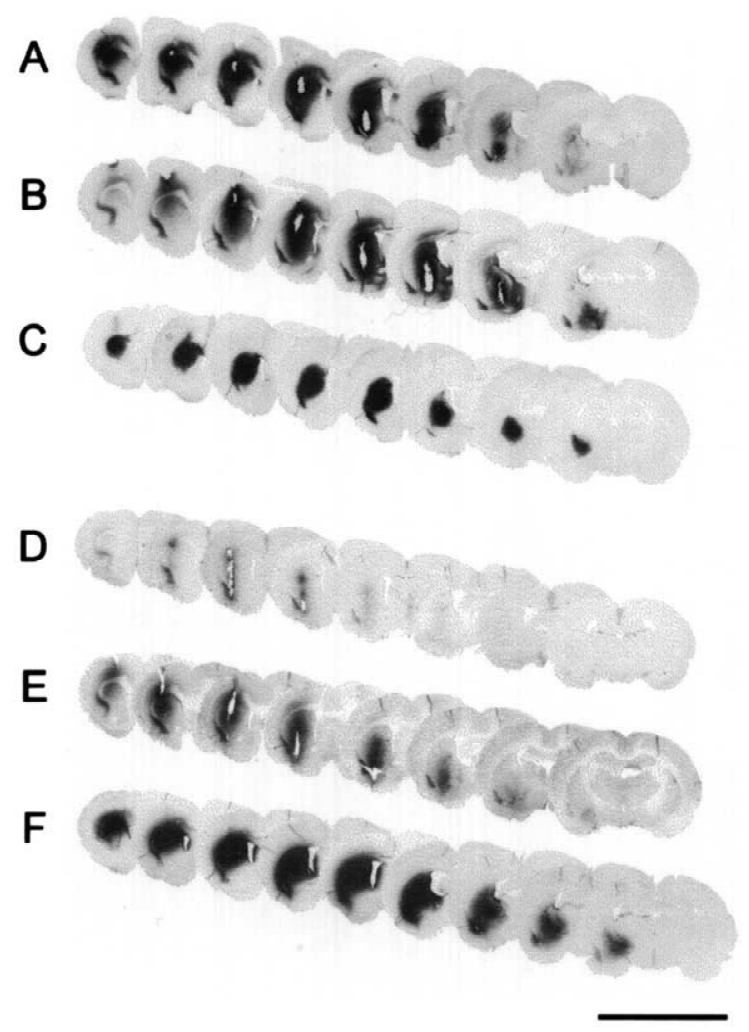

Fig. 1. Serial reconstruction of photomicrographs showing GDNF-immunostained striatal sections of rod- (A, D) and capsule-implanted (B, E), and lentiviral vector-injected (C, F) animals. Immunohistochemical analysis was performed at either 1 week (A-C) or 4 weeks (D-F) post-surgery. Scale bar, $1 \mathrm{~cm}$. 
encapsulated cells (Fig. 1E), and over $4 \mathrm{~mm}$ with lentiviral vectors (Fig. 1F). Only in the case of lentiviral vectors was GDNF staining observed beyond the striatum limits.

\subsection{Optical density of GDNF staining}

In order to quantify and compare the diffusion pattern of GDNF in the striatum using the three delivery methods, optical density of GDNF immunohistochemical staining was measured throughout the entire striatum using the NIH image analysis program (Fig. 2). One week post-surgery, optical density of GDNF staining obtained with rods (O.D.= $11.9 \pm 2.8$ ), capsules (O.D. $=11.8 \pm 1.3$ ) and lentiviral vectors (O.D. $=9.6 \pm 1.0)$ were not statistically different. At 4 weeks, however, both polymer rods and encapsulated cells showed a significant decrease in optical density (O.D. $=1.0 \pm 0.4$ and $4.7 \pm 0.6$, respectively), whereas lentiviral vectors led to a significant increase in optical density (O.D. $=20.7 \pm 1.7$ ) (Fig. 2).

\subsection{Volume of GDNF immunohistochemical staining in the striatum}

Using the same image analysis program, the volume of GDNF immunohistochemical staining was measured and compared to the ipsilateral striatal

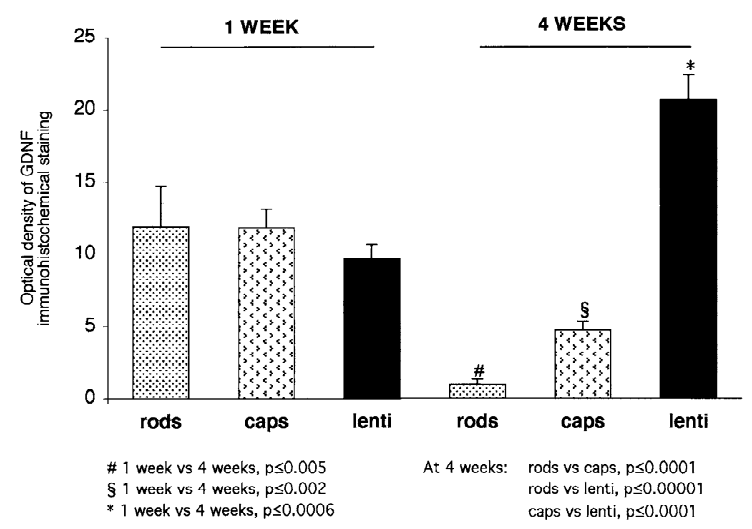

Fig. 2. Quantification of the total amount of detected GDNF based on the measurement of the optical density on GDNFimmunostained striatal sections at either 1 or 4 weeks post-surgery from rod- and capsule-implanted as well as lentiviral vectorinjected animals. Values are expressed as mean \pm S.E.M. volume. Interestingly, the ratio of the GDNF immunostaining volume and the estimated striatal volume was not statistically different between the rods, capsules and lentivirus $(53.5 \pm 8.4 \%$, $38.4 \pm 5.9 \%$, and $45.6 \pm 3.9 \%$, respectively) at the 1 week time point (Fig. 3). However, at 4 weeks post-surgery, the three methods were statistically different from the 1 week time point with a decrease in this ratio for the rods $(5.2 \pm 2.8 \%)$ and the capsules $(18.2 \pm 5.8 \%)$, and an increase for the lentivirus group $(72.8 \pm 4.5 \%)$. Similar results were obtained in cubic millimeters and compared to the estimated striatal volume (Table 1).

\subsection{Amount of hGDNF detected in the striatum}

In order to compare the maximum levels of hGDNF achieved by the different delivery methods, 2-mm-long striatal punches including the transplantation/injection site were taken and processed for ELISA assay. At 1 week post-surgery, $\sim 2$ ng GDNF per mg protein were detected with either rods, capsules or lentiviral vectors $(2.3 \pm 0.1,2 \pm 0.1$, and $2 \pm 0.1 \mathrm{ng}$ GDNF/mg protein, respectively) (Fig. 4). At 4 weeks post-surgery, the amount of GDNF released by the polymer rods dramatically decreased $(0.4 \pm 0.003 \mathrm{ng}$ GDNF/mg protein), whereas capsules and lentiviral vectors showed sustained and similar levels of GDNF around the injection site

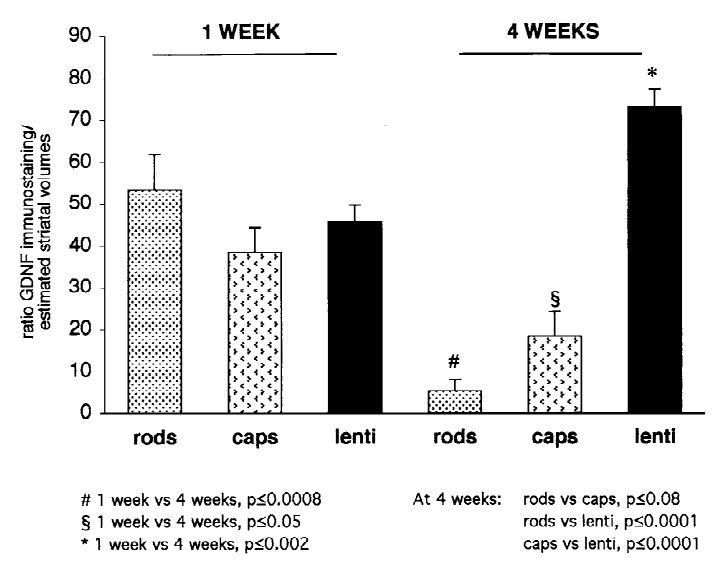

Fig. 3. Ratio of the volume of GDNF immunostaining and the estimated striatal volume at either 1 or 4 weeks post-surgery from rod- and capsule-implanted as well as lentiviral vector-injected animals. Values are expressed as mean \pm S.E.M. 
Table 1

Volume of GDNF immunohistochemical staining in the striatum and estimated striatal volume in $\mathrm{mm}^{3}$ at either 1 or 4 weeks post-surgery from rod- and capsule-implanted as well as lentiviral vector-injected animals. Values are expressed as mean \pm S.E.M.

\begin{tabular}{llrr}
\hline & & 1 Week & 4 Weeks \\
\hline Rods & GDNF immuno volume & $13.5 \pm 1.9 \mathrm{~mm}^{3}$ & $1.3 \pm 0.7 \mathrm{~mm}^{3}$ \\
& Striatal volume & $25.9 \pm 0.9 \mathrm{~mm}^{3}$ & $24.3 \pm 0.6 \mathrm{~mm}^{3}$ \\
Capsules & GDNF immuno volume & $10.3 \pm 1.6 \mathrm{~mm}^{3}$ & $4.8 \pm 1.5 \mathrm{~mm}^{3}$ \\
& Striatal volume & $27.1 \pm 1.4 \mathrm{~mm}^{3}$ & $26.4 \pm 0.6 \mathrm{~mm}^{3}$ \\
Lentivirus & GDNF immuno volume & $10.3 \pm 1.1 \mathrm{~mm}^{3}$ & $19.6 \pm 1.5 \mathrm{~mm}^{3}$ \\
& Striatal volume & $22.4 \pm 0.6 \mathrm{~mm}^{3}$ & $26.9 \pm 1.2 \mathrm{~mm}^{3}$ \\
\hline
\end{tabular}

$(1.7 \pm 0.3$ and $1.7 \pm 0.05 \mathrm{ng} \mathrm{GDNF} / \mathrm{mg}$ protein, respectively). At either 1 or 4 weeks post-surgery, contralateral values were similar to naive animals $(<0.15 \mathrm{ng} \mathrm{GDNF} / \mathrm{mg}$ protein), except for the lentiviral vectors, where small amounts of GDNF were detected at the 4-week time point $(0.5 \pm 0.3 \mathrm{ng}$ $\mathrm{GDNF} / \mathrm{mg}$ protein). The amounts of GDNF measured by ELISA assay represent maximum values in localized punches around the injection site and not absolute values within the entire striatum, thus explaining the discrepancies observed between Figs. 3 and 4 at the 4 -week time point between capsules and lentiviral vectors.

\section{Discussion}

In the present study, we have compared the efficiency of three different methods for delivery of the neurotrophic factor GDNF in the brain parenchyma of adult rats. Polymer rods, encapsulated cells and lentiviral vectors enable the continuous and

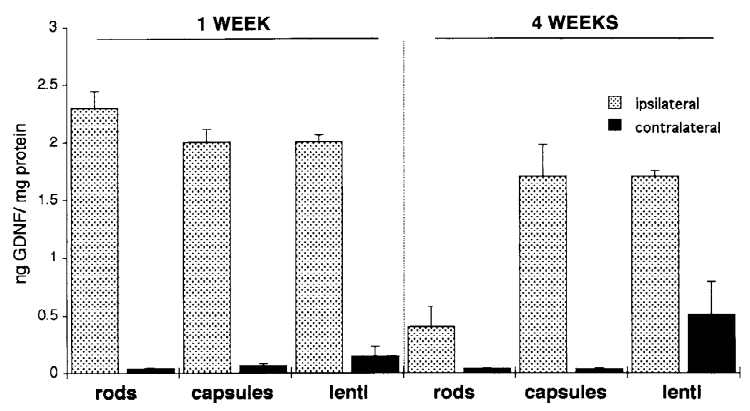

Fig. 4. Amount of hGDNF in the ipsi- or contralateral striatum measured by ELISA assay at either 1 or 4 weeks post-surgery from rod- and capsule-implanted as well as lentiviral vectorinjected animals. Values are expressed as mean \pm S.E.M. localized expression of significant amounts of GDNF in the striatum. Although the diffusion pattern of GDNF was approximately identical with the three approaches at 1 week post-surgery, results of the 4-week time point suggest that polymer rods are suitable for localized short-term protocols, whereas lentiviral vectors and encapsulated cells are more adapted methods for long-term applications.

Several studies have reported encouraging results using polymer rods releasing NTFs. Following a fimbria-fornix lesion, NGF released from EVA/BSA rods in the ipsilateral ventricle for 2 weeks prevented the loss of choline acetyltransferase expression in the medial septum and vertical diagonal band region [17]. More recently, Tornqvist et al. have demonstrated that polymer rods secreting NTFs such as epidermal growth factor, basic fibroblast growth factor and GDNF can enhance fetal dopaminergic graft survival, outgrowth, and functions, when coimplanted with a striatal fetal graft in a rat model of PD [18]. Consistent with our results, they found that polymer rods allowed the local secretion of the NTFs for $\sim 2$ weeks. Conceptually, polymer rods could be applied in a clinical setting especially as they are retrievable provided adequate geometry. Their use will, however, be limited to applications necessitating only short term delivery. As of today, EVA is also not approved for clinical use.

Several studies have shown the ability of encapsulated cells releasing NTFs to provide neuroprotection and neuroregeneration both in rodent [19-23] and primate $[24,25]$ models of neurodegenerative disorders. Scale-up in the human has already been achieved through a phase I clinical trial using intrathecal implantation of 5-cm-long CNTF-releasing capsules in end-stage amyotrophic lateral sclerosis patients [26,27]. The device was well 
tolerated and did not lead to significant side-effects. Viable and functional encapsulated cells were still observed 17 weeks post-implantation. One of the most promising applications of NTFs consists in the co-implantation of fetal mesencephalic cells with encapsulated cells releasing GDNF [20]. GDNF indeed increases the number of surviving dopaminergic neurons as well as enhancing the neurite outgrowth from these cells. Besides chronic delivery, the encapsulation technique also allows the treatment to be arrested in case of appearance of limiting side-effects as capsules are retrievable by a simple surgical procedure.

The present study reveals the ability of lentiviral vectors to lead to sustained delivery of GDNF in the rat striatum. GDNF staining was detected over a greater volume 4 weeks post-injection compared to 1 week. This observation is probably related to the long half-life of GDNF within the brain parenchyma. Previous experiments have reported long-term expression of the transgene up to 1 year in rodents [28] and 8 months in primates [15]. Long-term stable transgene expression is most probably related to the integration of the viral genome into the host chromosome [29]. Surprisingly, some GDNF was also detected in the contralateral striatum, as a result of chronic diffusion of the neurotrophic factor from multiple point sources suggesting that viral vectors lead to less localized delivery. Although no sideeffects were observed in our animals, the presence of detectable amounts of GDNF in the contralateral hemisphere might induce deleterious side-effects in humans, as previously described [9]. In this context, development of regulated lentiviral vectors to control GDNF production and thus avoid eventual sideeffects is required.

Lentiviral vector-mediated delivery of GDNF induces significant neuroprotection in various rodent models of PD [30,31]. Recently, we have reported both neuroprotective and neuroregenerative effects of GDNF delivery using lentiviral vectors in two different primate models of PD [15]. In contrast to ICV delivery of GDNF in PD patients, no side-effects of striatal delivery of GDNF was observed in these primates. However, clinical application of lentiviral vectors for the intrastriatal delivery of GDNF still requires the development of validated tests to detect replication-competent particles and, more important- ly, a system allowing the regulation of transgene expression in the advent of limiting side-effects. Encouraging preliminary results have already been obtained with lentiviral vectors encoding various transgenes under the tetracycline-inducing system $[32,33]$.

\section{Conclusion}

The present work reveals the efficiency of three different delivery methods in providing a significant amount of GDNF in the rat striatum. These data open interesting perspectives for the treatment of neurodegenerative diseases. The dose and the time during which GDNF needs to be administered, i.e. more detailed pharmacokinetics for the administration of this trophic factor in the CNS will require further investigations to determine which one of these approaches would be particularly relevant in a given clinical indication for the targeted neurodegenerative disease.

\section{Acknowledgements}

The authors thank Vivianne Padrun, Fabienne Pidoux, Maria Rey, Laurence Winkel and Christel Sadeghi for expert technical assistance. This work was partially supported by the Swiss National Science Foundation and the 5th European Framework Program "Neuroget".

\section{References}

[1] F. Hefti, Pharmacology of neurotrophic factors, Annu. Rev. Pharmacol. Toxicol. 37 (1997) 239-267.

[2] B. Connor, M. Dragunow, The role of neuronal growth factors in neurodegenerative disorders of the human brain, Brain Res. Rev. 27 (1998) 1-39.

[3] M.F. Haller, W.M. Saltzman, Localized delivery of proteins in the brain: can transport be customized?, Pharm. Res. 15 (1998) 377-385.

[4] P. Aebischer, J. Ridet, Recombinant proteins for neurodegenerative diseases: the delivery issue, Trends Neurosci. 24 (2001) 533-540.

[5] J.K. Morse, S.J. Wiegand, K. Anderson, Y. You, N. Cai, J. Carnahan, J. Miller, P.S. DiStefano, C.A. Altar, R.M. Lindsay, Brain-derived neurotrophic factor (BDNF) prevents the 
degeneration of medial septal cholinergic neurons following fimbria transection, J. Neurosci. 13 (1993) 4146-4156.

[6] Q. Yan, C. Matheson, J. Sun, M.J. Radeke, S.C. Feinstein, J.A. Miller, Distribution of intracerebral ventricularly administered neurotrophins in rat brain and its correlation with trk receptor expression, Exp. Neurol. 127 (1994) 23-36.

[7] L. Olson, A. Nordberg, H. von Holst, L. Backman, T. Ebendal, I. Alafuzoff, K. Amberla, P. Hartvig, A. Herlitz, A. Lilja et al., Nerve growth factor affects 11C-nicotine binding, blood flow, EEG, and verbal episodic memory in an Alzheimer patient (case report), J. Neural Transm. Park. Dis. Dement. Sect. 4 (1992) 79-95.

[8] M. Eriksdotter Jonhagen, A. Nordberg, K. Amberla, L. Backman, T. Ebendal, B. Meyerson, L. Olson et al., Intracerebroventricular infusion of nerve growth factor in three patients with Alzheimer's disease, Dement. Geriatr. Cogn. Disord. 9 (1998) 246-257.

[9] J.H. Kordower, S. Palfi, E.Y. Chen, S.Y. Ma, T. Sendera, E.J. Cochran, E.J. Mufson, R. Penn, C.G. Goetz, C.D. Comella, Clinicopathological findings following intraventricular glialderived neurotrophic factor treatment in a patient with Parkinson's disease, Ann. Neurol. 46 (1999) 419-424.

[10] K.D. Anderson, R.F. Alderson, C.A. Altar, P.S. DiStefano, T.L. Corcoran, R.M. Lindsay, S.J. Wiegand, Differential distribution of exogenous BDNF, NGF, and NT-3 in the brain corresponds to the relative abundance and distribution of high-affinity and low-affinity neurotrophin receptors, J. Comp. Neurol. 357 (1995) 296-317.

[11] C. Rinsch, E. Regulier, N. Déglon, B. Dalle, Y. Beuzard, P. Aebischer, A gene therapy approach to regulated delivery of erythropoietin as a function of oxygen tension, Hum. Gene Ther. 8 (1997) 1881-1889.

[12] N. Déglon, B. Heyd, S.A. Tan, J.M. Joseph, A.D. Zurn, P. Aebischer, Central nervous system delivery of recombinant ciliary neurotrophic factor by polymer encapsulated differentiated C2C12 myoblasts, Hum. Gene Ther. 7 (1996) 21352146.

[13] K. Moens, H. Heimberg, D. Flamez, P. Huypens, E. Quartier, Z. Ling, D. Pipeleers, S. Gremlich, B. Thorens, F. Schuit, Expression and functional activity of glucagon, glucagonlike peptide I, and glucose-dependent insulinotropic peptide receptors in rat pancreatic islet cells, Diabetes 45 (1996) 257-261.

[14] A.F. Hottinger, M. Azzouz, N. Déglon, P. Aebischer, A.D. Zurn, Complete and long-term rescue of lesioned adult motoneurons by lentiviral-mediated expression of glial cell line-derived neurotrophic factor in the facial nucleus, J. Neurosci. 20 (2000) 5587-5593.

[15] J.H. Kordower, M.E. Emborg, J. Bloch, S.Y. Ma, Y.P. Chu, L. Leventhal, J. McBride, E.Y. Chen, S. Palfi, B.Z. Roitberg, W.D. Brown, J.E. Holden, R. Pyzalski, M.D. Taylor, P. Carvey, Z.D. Ling, D. Trono, P. Hantraye, N. Deglon, P. Aebischer, Neurodegeneration prevented by lentiviral vector delivery of GDNF in primate models of Parkinson's disease, Science 290 (2000) 767-773.

[16] G. Paxinos, C. Watson, The Rat Brain in Stereotaxic Coordinates, Academic Press, London, 1998.

[17] D. Hoffman, L. Wahlberg, P. Aebischer, NGF released from a polymer matrix prevents loss of ChAT expression in basal forebrain neurons following a fimbria-fornix lesion, Exp. Neurol. 110 (1990) 39-44.

[18] N. Tornqvist, L. Björklund, P. Almqvist, L. Wahlberg, I. Stromberg, Implantation of bioactive growth factor-secreting rods enhances fetal dopaminergic graft survival, outgrowth density, and functional recovery in a rat model of Parkinson's disease, Exp. Neurol. 164 (2000) 130-138.

[19] J.L. Tseng, E.E. Baetge, A.D. Zurn, P. Aebischer, GDNF reduces drug-induced rotational behavior after medial forebrain bundle transection by a mechanism not involving striatal dopamine, J. Neurosci. 17 (1997) 325-333.

[20] J. Sautter, J.L. Tseng, D. Braguglia, P. Aebischer, C. Spenger, R.W. Seiler, H.R. Widmer, A.D. Zurn, Implants of polymer-encapsulated genetically modified cells releasing glial cell line-derived neurotrophic factor improve survival, growth, and function of fetal dopaminergic grafts, Exp. Neurol. 149 (1998) 230-236.

[21] J.L. Tseng, S.L. Bruhn, A.D. Zurn, P. Aebischer, Neurturin protects dopaminergic neurons following medial forebrain bundle axotomy, NeuroReport 9 (1998) 1817-1822.

[22] D.F. Emerich, S. Bruhn, Y. Chu, J.H. Kordower, Cellular delivery of CNTF but not NT-4/5 prevents degeneration of striatal neurons in a rodent model of Huntington's disease, Cell Transplant. 7 (1998) 213-225.

[23] D.F. Emerich, M.D. Lindner, S.R. Winn, E.Y. Chen, B.R. Frydel, J.H. Kordower, Implants of encapsulated human CNTF-producing fibroblasts prevent behavioral deficits and striatal degeneration in a rodent model of Huntington's disease, J. Neurosci. 16 (1996) 5168-5181.

[24] D.F. Emerich, S.R. Winn, P.M. Hantraye, M. Peschanski, E.Y. Chen, Y. Chu, P. McDermott, E.E. Baetge, J.H. Kordower, Protective effect of encapsulated cells producing neurotrophic factor CNTF in a monkey model of Huntington's disease, Nature 386 (1997) 395-399.

[25] V. Mittoux, J.M. Joseph, F. Conde, S. Palfi, C. Dautry, T. Poyot, J. Bloch, N. Deglon, S. Ouary, E.A. Nimchinsky, E. Brouillet, P.R. Hof, M. Peschanski, P. Aebischer, P. Hantraye, Restoration of cognitive and motor functions by ciliary neurotrophic factor in a primate model of Huntington's disease, Hum. Gene Ther. 11 (2000) 1177-1187.

[26] P. Aebischer, M. Schluep, N. Déglon, J.M. Joseph, L. Hirt, B. Heyd, M. Goddard, J.P. Hammang, A.D. Zurn, A.C. Kato, F. Regli, E.E. Baetge, Intrathecal delivery of CNTF using encapsulated genetically modified xenogeneic cells in amyotrophic lateral sclerosis patients, Nat. Med. 2 (1996) 696699.

[27] A.D. Zurn, H. Henry, M. Schluep, V. Aubert, L. Winkel, B. Eilers, C. Bachmann, P. Aebischer, Evaluation of an intrathecal immune response in amyotrophic lateral sclerosis patients implanted with encapsulated genetically engineered xenogeneic cells, Cell Transplant. 9 (2000) 471-484.

[28] L. Naldini, Lentiviruses as gene transfer agents for delivery to non-dividing cells, Curr. Opin. Biotechnol. 9 (1998) 457-463.

[29] E. Vigna, L. Naldini, Lentiviral vectors: excellent tools for experimental gene transfer and promising candidates for gene therapy, J. Gene Med. 2 (2000) 308-316. 
[30] N. Déglon, J.L. Tseng, J.C. Bensadoun, A.D. Zurn, Y. Arsenijevic, L. Pereira de Almeida, R. Zufferey, D. Trono, P. Aebischer, Self-inactivating lentiviral vectors with enhanced transgene expression as potential gene transfer system in Parkinson's disease, Hum. Gene Ther. 11 (2000) 179-190.

[31] J.C. Bensadoun, N. Déglon, J.L. Tseng, J.L. Ridet, A.D. Zurn, P. Aebischer, Lentiviral vectors as a gene delivery system in the mouse midbrain: cellular and behavioural improvements in a 6-OHDA model of Parkinson's disease using GDNF, Exp. Neurol. 164 (2000) 15-24.

[32] J. Reiser, Z.N. Lai, X.Y. Zhang, R.O. Brady, Development of multigene and regulated lentivirus vectors, J. Virol. 74 (2000) 10589-10599.

[33] T. Kafri, H. van Praag, F.H. Gage, I.M. Verma, Lentiviral vectors: regulated gene expression, Mol. Ther. 1 (2000) $516-521$ 